\title{
EL PSICODIAGNÓSTICO DE RORSCHACH DESDE UNA PERSPECTIVA INTERDISCIPLINARIA
}

\author{
RORSCHACH PSYCHODIAGNOSTIK FROM \\ AN INTERDISCIPLINARY PERSPECTIVE
}

\author{
Osvaldo Miranda Borges ${ }^{1}$, Alejandro Viñales Estrada ${ }^{2}$ \\ y Fidel Martínez Álvarez ${ }^{3}$
}

RECEPCIÓN: 08 DE OCTUBRE DE 2020

ACEPTACIÓN: 07 DE NOVIEMBRE DE 2020

\section{RESUMEN}

El presente artículo aborda algunos de los antecedentes históricos y fundamentos teóricos del Psicodiagnóstico de Rorschach desde una perspectiva interdisciplinaria. El Psicodiagnóstico de Rorschach es un método proyectivo que posibilita una caracterización integral de la personalidad con resultados objetivos, brindando al profesional de cualquiera de las esferas de actuación, una información amplia sobre los fenómenos psicológicos relativos a cada contexto y escenarios, en los cuales se puede aplicar este método: ámbito clínico, infantil, forense, socio-cultural, etnográico, organizacional, psicopedagógico, entre otros. El enfoque interdisciplinario permite analizar los nexos de las bases teóricas del método con sus formas de aplicación, según el contexto en el que se pretende realizar la transformación. Por tanto, el objetivo del trabajo está dirigido a fundamentar, desde la perspectiva interdisciplinaria, la utilidad psico-pedagógica del método de Rorschach.

Palabras clave: Psico-diagnóstico, método de Rorschach, perspectiva interdisciplinaria.

\begin{abstract}
The present article, approach several historical precedent and theorist base of Rorschach Psychodiagnostik by the interdisciplinary perspective. Rorschach Psychodiagnostik is a projective method that permits an integral characterization of personality with objective results given to the professional an extend information about the psychologists' process relating each context and site of application of this method: clinical ambit, childlike, forensic, socio-cultural, ethnographic, organization, psycho-pedagogic, between others. The interdisciplinary perspective permits us analyze the nexus of theoretic basis of method with its own ways of applications, according to the context of transformation. So the objective of this article goes to found, from the interdisciplinary perspective, the psychopedagogic utility of Rorschach method.
\end{abstract}

Keywords: Psychodiagnostik, Rorschach method, the interdisciplinary perspective.

1 Licenciado en Psicología de la Universidad de Camagüey (2009), Diplomado en Psico-diagnóstico de Rorschach en diferentes contextos de aplicación. Facultad de Ciencias Sociales y Humanísticas (2013) Psicólogo del Hospital Psiquiátrico "René Vallejo Ortiz" de Camagüey. Profesor Adjunto de la Universidad de Ciencias Médicas “Carlos J. Finlay” de Camagüey. Correo-e: osbaldom@nauta.cu

2 Licenciado en Estudios Socio-culturales de la Universidad de Camagüey (2007). Especialista del Centro Provincial de las Artes Escénicas de Camagüey. Profesor Adjunto de la Universidad de las Artes de Cuba. Filial de Camagüey. Correo-e: aleenano01@gmail.com

3 Doctor en Ciencias de la Educación (Universidad de la Habana, 2011), Máster en Estudios Sociales de la Ciencia y la Tecnología (Universidad de la Habana, 2000), Máster en Filosofía (Kiev, Ucrania, Unión Soviética, 1984), Profesor Titular Adjunto de la Filial de Camagüey de la Universidad de las Artes de Cuba. Correo-e: fidelmartinez@nauta.cu 


\section{INTRODUCCION}

La ciencia no es solo una disciplina de razón, sino también de romance y pasión. (HawKIng S., 2017, pág. 5)

En la actualidad la sociedad debe estar insertada como aspecto indispensable en los estudios y discusiones que se generen sobre la ciencia y los avances tecnológicos, por la propia influencia que ejerce la tecnología sobre el desarrollo social y cultural (Pacey, A., 1990), debiendo orientar los avances tecnológicos hacia la satisfacción de las necesidades sociales de la cultura que brinda dichas posibilidades de desarrollo en la educación (Núnez Jover, J., 1999)

Cuba, como parte del mundo, se ve afectada por los impactos sociales, culturales, políticos, filosóficos, económicos e ideológicos de la ciencia, la tecnología y la innovación tecnológica contemporáneas, de manera que una de las disciplinas que también ha recibido ese impacto es, precisamente, la Psicología, que al estudiar al hombre en sus múltiples facetas y manifestaciones en la vida puede mostrar que para lograr el pleno desarrollo del encargo social que la educación superior exige, es fundamental que sus profesionales logren una formación integral que les posibilite desenvolverse eficazmente frente a los retos y exigencias de la sociedad actual.

En el surgimiento y desarrollo de la Psicología como ciencia influyeron notablemente disimiles circunstancias, algunas de ellas se relacionan con la insuficiente explicación científica que la filosofía podía brindar sobre los fenómenos específicos de la psiquis y del comportamiento humano, también el acelerado desarrollo de la ciencia y la tecnología sobre todo en el siglo XIX, que hacia inevitable la necesaria capacitación y caracterización de los técnicos y obreros para ocupar determinados puestos de trabajo en los que eran necesarias habilidades específicas para el óptimo desempeño en la industria, y sobre todo, en el ámbito social donde se hacía imprescindible analizar al ser humano en diferentes contextos, como ente transformador de la naturaleza y la sociedad.

Entre los principales instrumentos con los que debe contar un profesional de la Psicología se encuentran las técnicas y métodos psicológicos para el estudio de la personalidad, dichos instrumentos se integran dentro de la carrera de psicología en la asignatura Psicodiagnóstico; precisamente, uno de los métodos fundamentales de estudio de la personalidad es el Psicodiagnóstico de Rorschach (Rorschach, Herman, 1966), el cual permite en un corto período de tiempo, sin obviar la necesidad de integrar o triangular el conocimiento obtenido por otras vías, una visión integral en el proceso de su caracterización.

En el diagnóstico inicial realizado, como estudio empírico preliminar de revisión bibliográfica (García Gutiérrez, Alberto, 2005, pág. 2), (Solís González, Y, 2004), de la educación superior, se pudo identificar algunas dificultades esenciales (patrones comunes para cualquier ámbito académico) en cuanto a la disposición y comportamiento de los estudiantes para afrontar las actividades docentes:

- Déficit en los niveles de bienestar.

- Inadaptación y desajuste psicológico del estudiantado al ambiente universitario.

- Aparición de conductas disruptivas dado el cambio de rutina y dinámica de la vida universitaria.

- Cambios cualitativos en las relaciones interpersonales.

- Apatía.

- Disminución de los niveles de tolerancia a situaciones estresantes.

- Trastornos del aprendizaje.

- Entre otras dificultades en el orden docente (González Collera, L, 1996), (Agramonte Rosell, Regina, 2003), (Solís González, Y, 2004), (Bonilla Vichot, I, 2005), (Velázquez Peña, E, 2006) 
El presente trabajo se sustenta en la concepción histórico-cultural de L.S. Vigotsky, ${ }^{4}$ así como en las ideas del sistema comprehensivo de John Exner del método de Rorschach, ${ }^{5}$ adecuado a la realidad cubana ${ }^{6}$ en general, y al proceso de diagnóstico psico-pedagógico de los estudiantes del nivel superior en particular.

Por las razones expuestas, se plantea como objetivo general del presente trabajo: fundamentar, desde la perspectiva interdisciplinaria, la utilidad psico-pedagógica del método de Rorschach.

\section{DESARROLLO}

\begin{abstract}
Soy un apasionado, a fin de ser capaz de hablar y de pensar; y si creo que hay en otro una aptitud natural para ver hacia lo uno y hacia la multiplicidad, lo persigo "por las huellas que deja tras sí como a un dios.
\end{abstract}

(Platón, 1972, pág. 876)

\section{Los fundamentos teóricos del método de Rorschach}

En el surgimiento y desarrollo del Psicodiagnóstico de Rorschach es expresión del condicionamiento histórico de las creaciones científico-tecnológicas, es decir, recibió el empuje de las realizaciones y prácticas populares, en las cuales, evidentemente, Rorschach se inspiró para elaborar su método de estudio de la personalidad, pues como señala uno de sus continuadores, el genio suizo: “. . al igual que la mayoría de los niños de su época, jugaba a menudo al popular juego llamado Klecknographie (Blotto) o juego de las manchas... El Blotto llevaba casi cien años jugándose en Europa en la época en que Rorschach comenzó su especialización en psiquiatría como médico residente, en 1909” (Exner, J, 1994, pág. 4)

Además, en el origen de tan ingenioso y útil método de diagnóstico influyeron, de manera decisiva, las demandas y necesidades de la capacitación y caracterización de los técnicos y obreros para ocupar determinados puestos de trabajo en los que eran necesarias habilidades para el óptimo desempeño en la industria, también en el ámbito social se hacía imprescindible analizar al ser humano en diferentes contextos (salud, educación y ámbito militar, entre otros). Por tanto, este método, como la mayoría de las creaciones científico-tecnológicas humanas, se ha desarrollado en función de las demandas sociales y exigencias del estudio de las enfermedades mentales (esquizofrenia), de las particularidades psicológicas de las personas para el empleo en el ámbito industrial y militar.

En concreto, el método Rorschach constituye una herramienta útil de transformación personal y colectiva, su dimensión esencialmente científica, radica en que es una fuente de producción de conocimientos en el ámbito de la psicología y psiquiatría, pues está constituido por un conjunto de presupuestos teóricos no solo establecidos por su creador, sino también enriquecido por sus continuadores, quienes han sistematizado sus ideas, principios y conceptos esenciales, tales como: caracterizar psicológicamente al individuo, mediante la identificación de los síntomas típicos de ciertas patologías que condicionan su comportamiento, así como de las interioridades de la subjetividad de la personalidad y sus conflictos fundamentales; a su vez, permite interpretar las motivaciones, intereses y proyecciones del estudiante en sus contextos docente, familiar y social.

4 Sobre la concepción histórico-cultural se utilizan los trabajos de: (Vigotsky, L.S., 1916/1972), (Vigotsky, L.S., 1924/2000), (Vigotsky, L.S., 1933/2004)

5 Los textos básicos representativos del sistema comprensivo del método de Rorschach aquí utilizados son: (Exner, J, 1994), (Exner, J.; Sendín,C., 1998), (Escobar, Javier, 2010)

6 Entre los autores cubanos que han difundido y han desarrollado adecuaciones específicas del sistema comprehensivo de John Exner del método de Rorschach, están: (Alonso, A.; et. al., 2003), (Fernández Olazabal, Pedro, 2004), (Pardillo Palomino, J, 2004), (Fernández Olazabal, P.; Pardillo Palomino, J., 2008) 
Las bases teóricas de este método se expresan también en un arsenal de conceptos psicológicos tales como: dimensiones cognitiva y afectiva del sujeto (afectividad) toma de decisiones, vivencias del sujeto en su entorno (Introversivo, extratensivo, coartado, ambigual), su clasificación según el tipo de respuesta a sus vivencias, que remiten a otros concepto tales como: la auto-percepción, las relaciones interpersonales, mecanismos de afrontamiento, capacidad de control, auto-regulación, tolerancia al estrés, entre otros.

\subsection{Antecedentes del psicodiagnóstico}

Aunque el concepto de psicodiagnóstico comienza a utilizarse en la psicología solo con la publicación del Rorschach en 1921, esta disciplina ya desde fines del siglo XIX evolucionaba de forma independiente.

Algunos autores reconocen a Gydeon como el precursor de las técnicas o métodos psicodiagnósticos, quien en el año 1622 aplicó un instrumento evaluativo con el fin de clasificar a los combatientes en la guerra de Israel contra Midia, instrumento que tuvo como objetivo primordial clasificar a los guerreros en dos categorías (López Angulo, L., 2010, pág. 1)

La determinación psicodiagnóstica de las particularidades de la personalidad solamente pudo evolucionar hacia un campo propio, después que en la psicología habían surgido condiciones imprescindibles para ello. La génesis de este campo puede concretarse desde las contribuciones de varias disciplinas y áreas de conocimientos, entre las que están: psicología experimental, diferencial, aplicada y la rama de la psicología relativa al desarrollo de los test o pruebas de caracterización y evaluación de la personalidad, entre otras.

En el desarrollo de la psicología experimental, ${ }^{7}$ se destacó W. Wundt (1832-1920), quien siguiendo los presupuestos y ensayos de su antecesor G.T. Fechner (1801-1887), ${ }^{8}$ pudo darle fundamentación científica a la psicología experimental, centrada en la tradición empírica y la metodología de las ciencias naturales de finales de siglo XIX, en especial, de la fisiología, la cual enfatizaba más el registro de las cualidades principales de los mecanismos neuro-fisiológicos, para determinar sus regularidades generales, mediante la utilización de modelos matemáticos.

En concreto, en esta área Fechner utilizó, para describir la relación entre el estímulo y la intensidad de la sensación, una función logarítmica, que permitió formular la primera ley cuantitativa de la psicología experimental; ${ }^{9}$ ley que constituyó un fundamento metodológico esencial, que sirvió

7 El término psicología experimental se refiere a determinados métodos de investigación en la psicología, creados fundamentalmente, entre otros, por Fechner y Helmholtz, representantes de la psicofisiología, siguiendo las ideas de Weber, este término se refiere al trabajo realizado por los que aplican métodos experimentales en el estudio del comportamiento y de los procesos que los sustentan. Los psicólogos experimentales emplean en sus investigaciones a seres humanos y animales para analizar procesos complejos como: sensaciones, percepciones, memoria, aprendizaje, entre muchos otros; su campo de aplicación dentro de la psicología también es muy variado. Sería necesario además plantear que la aparición de la psicología se asocia a la creación del primer laboratorio experimental dirigido por Wundt, profesor de la cátedra de filosofía (Alonso, A.; et. al., 2003), (Corral Ruso, R., 2003)

8 La influencia de Fechner se puede apreciar también directamente en la obra de Freud, en especial, en: "Más allá del principio del placer", quien planteaba que el principio del placer, derivaba del principio de estabilidad o de constancia de Fechner, quien afirmaba que el aparato psíquico tiende siempre a mantener las excitaciones procedentes del exterior en el nivel más bajo posible. Sin embargo, Freud postula el principio de repetición, el cual, en la vida animal, se manifiesta en una peligrosa estereotipia para los instintos (Robert, Marthe, 1967)

9 En esta ley llamada Ley de Weber, o Ley Weber- Fechner se estableció la fórmula: $S=K$. $\log$ E, significando que la intensidad de un estímulo físico sentida por un individuo se corresponde con una constante personal K, la cual se multiplica por el logaritmo de la intensidad del estímulo. De manera simple esta ley establece una relación cuantitativa entre la magnitud de un estímulo físico y cómo éste es percibido por el sujeto. (Corral Ruso, R., 2003) 
de base al psicodiagnóstico posterior y sus técnicas todavía hoy tienen vigencia (Alonso, A.; et. al., 2003, págs. 8-9)

El psicodiagnóstico no evolucionó directamente de la psicología creada por Wundt, porque este planteaba que las funciones psíquicas superiores, que son la esencia de la personalidad, no eran accesibles a la investigación experimental, ${ }^{10}$ de cualquier forma, resulta innegable que la propuesta de este investigador fue muy original y bastante novedosa para su época, en la cual exigía pasar de la fase de hipótesis y de la formación de conceptos psicológicos propiamente dichos, a una fase experimental, en la que sus presupuestos pudieran ser confirmados (Corral Ruso, R., 2003, pág. 66)

En paralelo, la psicología diferencial, rama de la psicología que se ocupa esencialmente de las diferencias individuales, fue otra rama de la psicología estrechamente relacionada al surgimiento del psicodiagnóstico, pues aportó elementos indispensables en lo relativo al estudio de las diferencias individuales; como planteó W. Stern, la psicología diferencial: ${ }^{11 ~ “ . . . ~ e s ~ l a ~ c i e n c i a ~ d e ~ l a ~ d i f e r e n c i a c i o ́ n ~ e s e n c i a l ~}$ de las funciones y características mentales” (Alonso, A.; et. al., 2003, pág. 9)

Por otro lado, la psicología aplicada rama de esta ciencia que tiene como propósito encontrar soluciones prácticas a problemas del comportamiento humano, constituyó otra fuente esencial del desarrollo del psicodiagnóstico. Entre sus principales representantes se encuentran: W. Will Scott, T. Witmer, H. Münsterberg.

En consecuencia, el psicodiagnóstico es un área muy importante de la psicología aplicada, más que todo, porque extiende las potencialidades del estudio integral de la personalidad en cualquiera de los ámbitos de la vida social como premisa para el desarrollo del desempeño profesional (Alonso, A.; et. al., 2003, págs. 14-16)Por tanto, con el paso de la investigación de lo individual al estudio integral de la personalidad, aparece el psicodiagnóstico como disciplina articuladora de unidad dialéctica entre ambos campos de indagación, que se ocupan de la tipología o caracterización de la personalidad.

A medida que el tiempo fue pasando la psicología se vinculó a la solución de tareas prácticas en diferentes ciencias y ámbitos de la vida social, entre las que se encuentran medicina, pedagogía, antropología, sociología, dirección organizacional, ética, lógica, metodología de la investigación, en las artes, entre otras.

\subsection{Origen y evolución del psicodiagnóstico de Rorschach}

Este método tuvo sus antecedentes en la historia y evolución del ser humano, desde que este intentaba explicar los fenómenos naturales a través de la magia; en su génesis indirectamente se encuentran las prácticas interpretativas de sacerdotes y magos de varias religiones primitivas, los cuales mediante ceremonias como el vertimiento de sangre sobre el suelo, o en alguna piedra ritual, intentaban predecir el futuro, o el momento adecuado para realizar determinada actividad como la cacería o enfrentarse a sus enemigos; también en la "lectura" que hacían de diferentes órganos al ser sacrificados los animales. Mientras que en otras latitudes preferían el lanzamiento de semillas al aire, la interpretación de las hojas de té, así como la observación de las nubes y las formas caprichosas que adoptan, todo lo cual tenía objetivos similares a los descritos anteriormente.

Posteriormente, influyeron las interpretaciones de los ideogramas, diseños y símbolos de los trabajos artísticos y científicos de Leonardo de Vinci, así como en las religiones y rituales, que intentaban comprender el significado de las cartas, caracoles, cocos, piedras, tableros, etc., Entre las más conocidas

10 El hecho de que Wundt no prefiriera las pruebas o test de comportamiento humano, pues estaba estudiando, preeminentemente, los procesos psico-fisiológicos, es lo que todavía intriga a muchos psicólogos actuales (Alonso, A.; et. al., 2003)

11 En el ámbito de la psicología muy a menudo se cita a Galton como fundador de la psicología diferencial con su obra " $L a$ psicología Diferencial" (1911), sin embargo, ya desde 1900 W. Stern había publicado su trabajo "Sobre la psicología de las diferencias individuales". 
están: el Tarot, la Regla de Ocha y la Santería, entre otras, las cuales influyeron en la preferencia de los seres humanos por la interpretación de formas ambiguas e imprecisas.

Es necesario destacar que en el surgimiento del método de Rorschach también incidieron las investigaciones que en los años 1895-1896, realizaron Alfred Binet, en colaboración con Víctor Henri, quienes idearon utilizar las manchas de tinta como tests psicológico o prueba de imaginación visual para el estudio de la inteligencia (López Vázquez, A, 2015, pág. 11)

En los antecedentes del método Rorschach, como técnica proyectiva, influyó poderosamente la denominada prueba de "asociación de palabras", descrita por Galton en 1879 y, originalmente, conocida como "prueba de asociación libre", la cual, es considerada la primera de carácter proyectivo de la historia. Entre las grandes figuras de la psicología que la enriqueció estuvo Carl Gustav Jung.

Para la creación de su método Rorschach tuvo en cuenta la tesis doctoral del estudiante polaco de medicina Syzmond Hens, que fue publicada entre finales de 1917 y los inicios del 1918, quien fuera discípulo de Bleuler. En concreto, Hens había ideado su propia serie de ocho manchas de tinta, que administró a niños, y adultos sanos y enfermos. La tesis estudiaba las similitudes y diferencias en el contenido de las respuestas de estos tres grupos, y sugería que un sistema de clasificación del contenido de las respuestas podría resultar útil desde el punto de vista diagnóstico (Exner, J, 1994, págs. 3-5)

En verdad, las diez manchas de tinta, que constituyen los estímulos de esta técnica de Herman Rorschach (1884-1922), aparecieron en 1921 en su artículo, titulado: "Método y resultados de una experiencia psicodiagnóstica de percepción o interpretación libre de formas fortuitas", texto que luego fue publicado bajo el nombre de "Psychodiagnostik". ${ }^{12}$

Esta prueba fue concebida inicialmente para el estudio de la percepción en la esquizofrenia, al plantearse Rorschach la hipótesis sobre la existencia de diferencias esenciales en la percepción de este tipo de enfermedad psiquiátrica. El método fue luego aplicado al estudio de la percepción en escolares adolescentes sanos con la finalidad de compararlos, como grupo de control, con los enfermos (Pardillo Palomino, J; Fernández Olazabal, P., 2001)

Desde entonces el método ha suscitado gran interés y ha sido muy investigado y utilizado en diferentes contextos sociales, en especial, en el ámbito de la práctica clínica donde tuvo su origen, también se desarrolló en otros entornos como en la educación, en la práctica de la psiquiatría general y forense, en los estudios socio-culturales y en la selección de personal para el diagnóstico organizacional en diferentes profesiones.

La muerte prematura del creador impidió la culminación personal de su obra. La difusión de las manchas originales corrió por cuenta de sus colegas y amigos en lo personal, quienes, además de difundirlas, estimularon su estudio y desarrollo. En Europa se destaca la escuela suizo-alemana, también llamada clásica u ortodoxa, representada por W. Morgenthaler, H. Zulliger y E. Bohm, la cual ha contribuido enormemente al desarrollo del método y se mantuvieron adheridos a la técnica original del creador, sobre todo en lo concerniente al estudio de la esquizofrenia.

En Norteamérica por su parte se desarrollaron los llamados cinco grandes sistemas Rorschach de: Klopfer, B., Beck, S., Piotrowski, Z., Hertz, M. y Rappaport, D. Schafer, R., quienes aportaron el perfeccionamiento del análisis cuantitativo y cualitativo del método, que permitió el enriquecimiento de su nomenclatura, mediante la creación de tablas para su calificación.

12 Herman Rorschach no se propuso la creación de una prueba en sí misma, en sus inicios consideraba su monografía solo como un resultado previo de su investigación, posteriormente, aceptó el término psicodiagnóstico con fines puramente comerciales, es importante destacar además que en el ámbito académico los test psicológicos hicieron su aparición oficialmente en el siglo XIX, porque se conoce que ya desde 1622 se habían utilizado instrumentos con el fin de clasificar a los sujetos, pero el psicodiagnóstico surgió en el siglo XX luego de la publicación de su célebre monografía (Rorschach, Herman, 1966) 
Actualmente, se destaca en el ámbito internacional el Sistema Comprehensivo de la escuela de Jonh Exner, que se caracteriza por un minucioso trabajo en el campo de la investigación cuantitativa, que ha aportado una nomenclatura nueva y un sistema categorial innovador.

En Latinoamérica, el enfoque de John Exner ha sido aplicado en diferentes ámbitos; por ejemplo, en $\mathrm{Cuba}^{13}$ ha sido adecuada al estudio de caracterización de enfermos mentales, criminales, miembros de familias disfuncionales, líderes de comunidades étnicas y escolares adolescentes, entre otros.

En esencia, "... el Rorschach actual nos ofrece una visión diferente a la tradicional en las aplicaciones y el uso del método. Sobrepasados los límites del contexto clínico, se ha convertido en un espacio del saber y de la investigación que penetra en los contextos pedagógicos, socioculturales, etno-psicológicos y sociales en general" (Pardillo Palomino, J, 2004, pág. 11)

Por tanto, el método de Rorschach tiene enormes potencialidades para el estudio integral de la personalidad en los más disímiles contextos sociales y ámbitos académicos, tales como: familia, comunidad, entornos institucional y organizacional, escuela, salud, cultura, arte, deportes, empleo y educación.

\section{El método Rorschach en diferentes esferas de actuación desde la perspectiva interdisciplinaria}

El comportamiento humano se considera como un todo estructurado, irreductible a sus elementos o componentes; algo que, por esa misma razón, exige métodos que respeten las estructuras psíquicas humanas, se adapten a ellas y sean capaces de estudiarlas y comprenderlas.

(Martínez Miguélez, M., 1996, pág. 3)

A mediados del pasado siglo, aproximadamente en la década de los cincuenta, ya se percibía la necesidad de lograr la interdisciplina, fue entonces cuando Georges Gusdorf planteó un proyecto con ese carácter para las ciencias humanas, patrocinado por la UNESCO (Fiallo Rodríguez, Jorge, 2003)

Desde este referente se precisa abordar toda una serie de fenómenos naturales, sociales y del pensamiento desde su integridad y totalidad, ya que se ha reconocido que desde una ciencia en particular no ha sido posible conocer o dar solución a los complejos problemas que presenta la realidad educativa.

En cuanto a su origen etimológico el prefijo inter se refiere a la formación de palabras, sean sustantivas o adjetivas con significado de: entre, en medio de algo. No obstante, existen otras connotaciones, por ejemplo, el significado de cambio y reciprocidad entre las áreas de conocimientos.

Así también, la palabra disciplina tiene varios significados, entre los cuales están: doctrina, instrucción de una persona, esencialmente en lo moral, regla de enseñanza impuesta por un maestro a sus discípulos o el de asignatura, aunque a partir del propio uso se relaciona con el de conocimiento, enseñanza, instrucción, método, ciencia, etc.

13 En Cuba la utilización y adecuación endógena del método de Rorschach tienen una larga tradición desde la década de los ańos cuarenta del pasado siglo," ... de esta fecha y hasta la década del 70 floreció el uso del método y se generalizó al nivel universitario y de práctica asistencial estatal. En los años 60 y 70 surgen figuras que impulsaron el desarrollo del método, C. De La Torre, R. Arce, CB.M López, N. Pérez Valdés, M. Ríos, C. Cunill, E. Salazar, A. Jordán, E. Praderes, J. Portuondo, A M. Duque de Estrada, A. Guerra, V. De Rojas, J. Dueñas, J. Pardillo y otros, básicamente en el contexto asistencial e investigativo. $L a$ docencia se mantuvo en la Facultad de Psicología, en el pregrado con C. De la Torre y $R$. Arce, al nivel de postgrado con A. Alonso. En Camagüey, O. Alonso, y MO. Granela, que con su labor asistencial y docente mantuvieron el uso del método y la formación de los rorscharchistas camagüeyanos" (Pardillo Palomino, J, 2004, pág. 9) Incluso, hoy se habla ya de una perspectiva propiamente cubana de la aplicación del sistema comprensivo del método de Rorschach. Propuesta que hoy se le denomina "Sistema cubano integrador explicativo del Método Rorschach", que considera las particularidades del contexto social de la mayor de las Antillas (Fernández Olazabal, Pedro, 2004), (Pardillo Palomino, J, 2004), (Fernández Olazabal, P.; Pardillo Palomino, J., 2008) 
En esencia, por interdisciplina se entiende a un determinado nivel de desarrollo organizacional de las disciplinas y áreas de conocimientos más complejo que el nivel de la multidisciplina, en el que se establecen objetivos comunes; en esa articulación se produce intercomunicación y enriquecimiento recíprocos y hasta transformaciones de orden metodológico en los planos de la investigación y la docencia, de manera que se producen soluciones mejores que en la multidisciplina, pero todavía transitorias y limitadas de los problemas de la realidad.

Entre los elementos más distintivos de la Interdisciplina se encuentran:

1. Un nivel más complejo de integración de disciplinas (nexos más extendidos, profundos y duraderos que en la multi y pluridisciplina)

2. Es una actividad más compartida y participativa que propicia la aparición de un líder, aunque todavía sigue siendo impuesta regularmente "desde arriba".

3. Ya aparecen términos comunes y se crean híbridos interdisciplinares.

4. Sin abandonar sus paradigmas cognitivos propios se logran mejores métodos, técnicas y procedimientos más creativos y mixtos.

5. Las acciones tienen mayor eficacia que la multidisciplina, que alcanza un mayor impacto en la solución de los problemas complejos (Martínez Álvarez, Fidel, 2011, pág. 140)

Desde la perspectiva interdisciplinaria se puede afirmar que el Psicodiagnóstico de Rorschach es muy utilizado para el estudio del ser humano en múltiples esferas de actuación, debido a las posibilidades que ofrece en los aspectos técnicos, descriptivo, psicopatológicos y, fundamentalmente, para la caracterización de la personalidad.

En concreto, la amplia gama de espacios para la utilización del Rorschach en diferentes contextos ha consolidado el criterio de que se constituye en un método de estudio integral de la personalidad y con capacidad de adecuación a diferentes contextos organizacionales (instituciones, organizaciones, grupos, comunidad y familia), teniendo en cuenta estos criterios se considera que el Rorschach se ubica dentro de los métodos particulares de investigación, ${ }^{14}$ según Pardillo Palomino (2004), también incluye aspectos más profundos y generales, ${ }^{15}$ apreciándose un gran avance en el desarrollo del instrumento desde otras disciplinas y perspectivas, ${ }^{16}$ tales como:

\section{a) En la psicología clínica o de la salud}

Es en esta esfera de aplicación donde el Psicodiagnóstico de Rorschach surgió y donde ha tenido mayor desarrollo y sistematización de sus presupuestos. Cuando su autor lo creó en el año 1921 centró su investigación en el aspecto psicopatológico, por supuesto en el ámbito clínico, específicamente en las diferentes clínicas psiquiátricas donde Herman Rorschach desarrollaba intensas labores asistenciales, las cuales combinaba con las investigativas. Este autor había notado las enormes diferencias percep-

14 Al respecto Pardillo Palomino afirma que: ”... en alguna medida la amplia gama de espacios para la utilización del Rorschach en diferentes contextos ha generado el criterio de que se constituye en método de investigación, este autor considera que el Rorschach se ubica dentro de los métodos de investigación de una ciencia particular: la Psicología, se considera al Rorschach como un método particular, que tributa a la solución de problemas y a lo proyectivo" (Pardillo Palomino, J, 2004, pág. 18)

15 Este mismo autor plantea que: "El nivel de generalización y profundidad del método siempre superará al del test, el método es mucho más, es la modalidad, los esquemas y estilos mentales para la penetración gradual del sujeto cognoscente en la realidad. El test es la técnica para obtener información, además apela a un aspecto de la personalidad con menor grado de generalidad. El Rorschach como todo método está formado por diferentes técnicas, como son técnicas para la aplicación, interpretación, y análisis, se diferencia de los test en que los supera en grado de generalidad". (Pardillo Palomino, J, 2004, pág. 18).

16 Recuérdese que el método de Rorschach surgió en el ámbito clínico en el año 1921, centrando su creador su investigación en el aspecto psico-patológico fundamentalmente, para determinar la percepción diferenciada y distorsionada de los esquizofrénicos con respecto a las personas sanas; posteriormente se ampliaron las posibilidades casi ilimitadas para la utilización de este método en otras ciencias. 
tivas de los pacientes esquizofrénicos en las respuestas dadas ante los estímulos que constituían las láminas con las conocidas manchas y logró establecer múltiples diferencias con un grupo de control que realizó con adolescentes y adultos sanos, posteriormente sus seguidores continuaron su utilización fundamentalmente en el aspecto clínico y psicopatológico.

Múltiples son los beneficios que aporta este método en la psicología clínica, de la salud, en la psiquiatría, etc. Algunos de estos beneficios se pueden resumir de la forma siguiente:

- Permite ubicar eficazmente a los individuos en alguno de los niveles de funcionamiento, para lo cual es muy utilizado en el ámbito de la psiquiatría. ${ }^{17}$

- Es efectivo para identificar diferentes trastornos a nivel de pensamiento, afectos, conducta, etc.

- Brinda una aproximación muy acertada del nivel intelectual de la persona evaluada, a través de múltiples indicadores identificados en el protocolo.

- Al ser una prueba proyectiva, la persona no solo exterioriza su organización básica de personalidad, si no que proyecta sus conflictos intra-psíquicos.

\section{b) En la investigación socio-cultural (antropológica y etnográfica)}

El propio Herman Rorschach desde la creación de su método apreciaba que existían diferencias sustanciales de tipo cultural aun dentro de una misma región y planteaba que "... el tipo vivencial ha de ser también muy distinto en los diferentes pueblos y razas; con toda seguridad, discrepará en un inglés, un alemán, o un ruso de 40 años; pero las divergencias serán aún mayores en sujetos de distintas razas" Rorschach, H., 1966, tomado de: (Pardillo Palomino, J; Fernández Olazabal, P., 2001, pág. 91)

En nuestro país también se han realizado investigaciones socioculturales con el método, en los cuales sus autores plantean que dichos estudios en el campo del Rorschach tienen su génesis en un principio fundamental que es la interrelación entre personalidad y cultura, entendida la cultura como un aspecto integrante del medio, la cual forma parte de la conciencia social y del sistema de influencias de las que el sujeto se va apropiando desde los inicios desde sus primeras etapas del desarrollo cognitivo-emocional (Pardillo Palomino, J; Fernández Olazabal, P., 2001, pág. 86)

\section{c) En la dirección y psicología organizacional}

La utilidad del método de Rorschach en el ámbito organizacional se expresa fundamentalmente, cuando la caracterización de la personalidad de los sujetos es importante para los propósitos de diseñar un plan de formación, o capacitación, de una determinada carrera profesional, o cuando se requiera tomar otras decisiones importantes relacionadas con el sujeto (por ejemplo, en procesos de selección de personal, para ocupar un determinado puesto de trabajo de acuerdo a las capacidades individuales y a las exigencias del puesto). Pocos procedimientos de evaluación pueden capturar la singularidad de una persona como la hace el Rorschach cuando es utilizado y evaluado apropiadamente.

El tipo de tarea que se realiza en la administración del Rorschach estimula la resolución de problemas y toma de decisiones bajo las condiciones más bien inusuales que se producen al observar las manchas de tinta en las láminas. Para llevar a cabo esas decisiones el sujeto pone en marcha un conjunto muy complejo de mecanismos psicológicos, y por esa razón las respuestas suelen reflejar características personales, tal como se organizan y activan en las tomas de decisiones de la vida cotidiana en general y en la vida laboral en particular. Muchas de estas características no resultan aparentes a los observadores de la conducta (cotidiana o laboral), ya que lo que se observa son los productos de los procesos psico-

17 Este es uno de los criterios fundamentales de la indicación del método a los pacientes en el ámbito de la psiquiatría y la psicopatología, pues el Rorschach ubica a los sujetos en uno de los cuatro niveles de funcionamiento existentes (neurótico, psicótico, psicopático, o deficitario), haciendo énfasis en los dos primeros por su importancia para la adaptación al medio circundante. 
lógicos, es decir, se observan comportamientos. Los hallazgos del Rorschach reflejan, principalmente, los procesos generadores de esos comportamientos.

d) En el área de la psico-pedagogía.

Es imprescindible saber qué ocurre en el alumno, cómo aprende ese alumno, qué
le interesa saber a ese alumno, ya que es él en última instancia quien determina el
éxito o fracaso del proceso de enseñanza-aprendizaje. (Bonilla Vichot, I, 2005, pág. 2)

Una de las ciencias estrechamente relacionada con la psicología es la pedagogía, en la cual se toma en cuenta la individualidad del estudiante, pero sin obviar que este proviene de una familia determinada, de un medio cultural específico y con un sistema de creencias e ideología que es necesario tener en cuenta al momento de caracterizar, evaluar o atender.

Este método es uno de los instrumentos que se puede utilizar para realizar una evaluación integral, o proceso de caracterización, que aporte una información amplia y confiable sobre la personalidad del estudiante, sus potencialidades o debilidades (entendidas estas como inadaptación al entorno y exigencias del medio docente), sus dificultades en el desarrollo, formas de aprendizaje, particularidades individuales de los estudiantes, áreas o esferas de conflictos, formación vocacional, motivaciones e intereses y posibles trastornos del aprendizaje. Es decir, en la educación superior se debe realizar por el profesor un estudio detallado de caracterización o diagnóstico integral de los factores que condicionan el comportamiento complejo del grupo estudiantil (González Soca, Ana María, 2002, pág. 72)

Además, el Psicodiagnóstico de Rorschach puede brindar en un tiempo relativamente breve información muy valiosa sobre los estudiantes y así los profesores podrán realizar una estrategia individualizada de superación o compensación de los problemas identificados. La estrategia capacita a los docentes para que promuevan el re-aprendizaje de conductas adaptativas de los estudiantes, que les faciliten el ajuste al medio docente, fortaleciendo en ellos los mecanismos de afrontamiento de conflictos en la vida universitaria.

Por tanto, es muy importante implementar una estrategia de superación, mediante la cual los profesores puedan resolver las dificultades identificadas con el método. Ante todo, se debe determinar el significado de estrategia de superación, la cual consiste en un programa de dirección psico-pedagógico para la transformación del contexto educativo, desde un estado real hasta un estado deseado, lo que presupone, ante todo, realizar un diagnóstico integral de los profesores con la finalidad de identificar y resolver la problemática en cuestión, así como la proyección y ejecución de metodologías y sistemas de actividades y acciones concretas, en diferentes formas de organización docente (curso, entrenamiento, adiestramiento, asesoría, taller, etc.), las cuales tienen un carácter progresivo y coherente, dirigida a alcanzar de forma paulatina los objetivos propuestos (De Armas Ramirez Nerely, 2003)

De manera que, a partir de las dificultades detectadas en el diagnóstico, la estrategia de superación se implementaría en función de que los profesores guíen a los estudiantes desde la situación en la que se encuentran hasta aquella que les permita alcanzar los objetivos fijados en los aspectos técnicos y profesionales, así como de su propio desarrollo individual.

Ahora bien, en el proceso de diagnóstico seria de enorme valor metodológico complementar los hallazgos obtenidos a través del método Rorschach. Por ejemplo, con la propuesta de Solís González, se puede desarrollar las cualidades profesionales de los estudiantes, pues propone perfeccionar la orientación hacia un riguroso y sistemático auto-diagnóstico, el cual les permitirá profundizar en el conocimiento de sí mismos, en sus logros, dificultades y potencialidades (Solís González, Y, 2004). 
Gracias a ello, el profesor puede facilitar y orientar las actividades necesarias para, conjuntamente, construir las estrategias de aprendizaje de los estudiantes, en función de las dificultades detectadas en el psico-diagnóstico integral de su personalidad.

Además, desde la perspectiva integradora del método, sería muy útil para el profesor realizar otras actividades complementarias de diagnóstico de cada estudiante, promoviendo encuentros que enriquezcan el análisis de las potencialidades para el proceso de aprendizaje. En correspondencia con los resultados obtenidos, estudiantes y profesores pueden orientarse mejor hacia el perfeccionamiento de los procesos cognitivos y afectivos, mediante nuevos métodos de activación de la enseñanza y nuevas estrategias de aprendizaje (Solís González, Y, 2004, pág. 83), (Esquijarosa Chirino R., et al, 2014, págs. 3-4)

En concreto, el método Rorschach puede contribuir a la activación de los procesos de enseñanza y elevar el nivel de motivación de los estudiantes para el auto-aprendizaje o la metacognición, ${ }^{18}$ todo lo cual redundará en su mayor robustez adaptativa (resiliencia), al ámbito educacional, mediante el fortalecimiento de los mecanismos de afrontamiento de los conflictos personales y colectivos.

Desde la concepción del método y de otros referentes teóricos, los recursos y mecanismos de afrontamiento de conflictos constituyen aquellas capacidades y actitudes conscientes de la personalidad, que permiten al docente orientar a cada estudiante las vías para encontrar las soluciones pertinentes y eficaces a los problemas que se le presentan en el proceso docente y en aquellas actividades extracurriculares en la familia y la comunidad, las cuales puedan obstaculizar su desempeño personal y el desarrollo de su colectivo estudiantil.

En esencia, afrontar significa una actitud reflexiva ante los problemas, no de enfrentamiento, sino de adecuación adaptativa o resiliencia fundada en la capacidad de modificar (fluctuaciones interna del sistema) la dinámica de las relaciones intra e interpersonales para potenciar la inteligencia emocional del estudiante y contribuir a la empatía comunicacional en el colectivo estudiantil (inteligencia organizacional), como vía para fomentar la cooperación y el trabajo en equipo de los estudiantes, así como su adaptación creativa ante los problemas (Fried Schnitman, Dora y Mario Rodriguez-Mena García, 2011)

Desde esta perspectiva del afrontamiento de los conflictos el profesor, como facilitador y orientador de los procesos docentes, debe dinamizar las relaciones participativas y creativas de los estudiantes para fomentar la auto-organización, auto-poiesis y sinergia del grupo de clases (Maturana, H; Varela, F, 1971/1995)

Por tanto, en el estudio integral de la personalidad y de la inteligencia del sujeto juegan un significativo papel las propuestas heurísticas y la amplia variedad de indagaciones proyectivas que proporciona el método, tales como:

- El estudio de los procesos dinámicos o de las cinestesias, ${ }^{19}$ que se expresan en movimientos inherentes de las figuras proyectadas por el sujeto en las láminas, mediante sus respuestas; además, estos son movimientos que se manifiestan en dos variantes: activos y pasivos. Desde estos primeros indicadores de la percepción dinámica del sujeto ya se puede iniciar la caracterización de su nivel de desarrollo intelectual.

18 A lo largo de la historia existen diferentes concepciones que enfatizan la necesidad del proceso de auto-aprendizaje o meta-cognición. Entre los autores que fundamentan esta temática están: (González Maura, Viviana; Castellano Simons, Doris, 1995), (Canfux Sanler, Verónica; González Pacheco, Otmara; et. al., 1995)

19 El término cinestesia también se denomina por otros autores en otras áreas de conocimientos como kinestesia o cinemática, definiciones de procesos análogos relacionados con el movimiento de imágenes, figuras y secuencias visuales, que forman una concepción dinámica a partir del estudio del acople (estructura) y sincronía (función) entre las partes de un sistema. 
- A su vez, el número de respuestas y el grado de complejidad de los determinantes ${ }^{20}$ permiten inferir también con cierta certeza el nivel de desarrollo intelectual del sujeto.

- Es muy importante determinar la amplitud del contenido ${ }^{21}$ de las respuestas, pues indican la riqueza imaginativa y creativa del sujeto.

- El método permite determinar el nivel de desarrollo de ciertas operaciones lógicas del sujeto, tales como: comparación, analogía, diferenciación, análisis, síntesis, generalización, etc., en especial, su capacidad de abstracción. ${ }^{22}$

- Además, un sujeto con elevado desarrollo intelectual brinda mayor cantidad de respuestas con mayor poder de síntesis, ${ }^{23}$ en las cuales logra la integración de dos o más partes o detalles de las figuras en la lámina, que revelan sus interacciones.

- Así también, los estudiantes que logran una sucesión ordenada de las respuestas, denotan un estilo particularmente organizado de estructurar los mecanismos de afrontamiento cognitivos de los problemas de la realidad.

- A su vez, cuando predominan las respuestas globales, ${ }^{24}$ los estudiantes evidencian mayor poder de síntesis y otras habilidades intelectuales más desarrolladas.

- Además, es de especial importancia el estudio del tiempo de reacción ${ }^{25}$ de los estudiantes ante las preguntas del examinador, pues aquellos que tienen la capacidad de reacción más rápida tienden a ser más ingeniosos y talentosos (desarrollo de la agilidad mental).

En lo relativo al estudio del nivel de desarrollo de la inteligencia en los sujetos hay algunos autores que resaltan otras ventajas del método de Rorschach, aplicables en el ámbito docente, tales como:

- Los resultados que proporciona la aplicación del método son regularmente independientes del grado de aprendizaje escolar o académico del sujeto. Esta es una idea algo cuestionable, pero se reconoce el sentido de que los avances académicos del estudiante no interfieren directamente en el proceso de caracterización integral de su personalidad.

- Los datos del test son objetivos y sencillos en su presentación. Esto también es cuestionable, dado que no existe la objetividad absoluta, siempre los datos tendrán una naturaleza comple-

20 Por determinantes se entienden aquellos elementos que condicionan la respuesta del sujeto, es decir, remite a la característica fundamental que motivó directamente la respuesta del examinado. La evaluación de los determinantes se realiza en la segunda fase de la aplicación del método, que se le denomina fase de interrogatorio. El examinador debe considerar el valor de la espontaneidad en las respuestas del sujeto, evitando así la posible influencia del propio examinador en las respuestas del examinado. Los determinantes pueden ser: forma $(\mathrm{F})$, color cromático o acromático $\left(\mathrm{C}, \mathrm{C}^{\prime}\right)$, movimientos humanos, animales, inanimados $(\mathrm{M}, \mathrm{FM}, \mathrm{m})$, regularmente interrelacionados entre sí, por lo que se amplía la variedad de determinantes.

21 Las categorías del contenido expresan la amplitud conceptual del individuo, sus principales motivaciones e intereses, ya que en el contenido se revela influencia de la cultura sobre el sujeto. Existen múltiples contenidos codificados en el Rorschach, estos pueden ser contenidos humanos $(\mathrm{H})$, animales (A), paisaje (Ls), naturaleza (Na), entre muchos otros. La utilización de algunos de estos contenidos comenzó con las escuelas posteriores a la creación del método.

22 La capacidad de abstracción es de vital importancia en el estudio del nivel intelectual del individuo. Este último proceso se aprecia muy disminuido en las personas con déficits o afectaciones del nivel intelectual, quienes tienen muchas dificultades con la capacidad de determinar las propiedades y cualidades esenciales de los fenómenos y las cosas sin tenerlos presentes.

23 Este aspecto se evalúa en la calidad evolutiva de las respuestas. La calidad evolutiva refleja el nivel de funcionamiento cognitivo, la intención o la capacidad del sujeto evaluado de analizar y sintetizar el campo estimular asignándole un significado. Generalmente las respuestas de síntesis se dan con mayor frecuencia en sujetos más talentosos.

24 En el lenguaje especifico del método Rorschach se nombran respuestas globales a aquellas que utilizan toda el área de la figura en la lámina, este tipo de respuesta supone en algunos casos un gran esfuerzo de síntesis o integración; también es necesario destacar que una respuesta que no sea global no implica necesariamente que no tenga suficiente calidad.

25 Este aspecto permite inferir un adecuado funcionamiento cognitivo, sobre todo de las asociaciones y del pensamiento del sujeto en sus procesos fundamentales. 
ja, probabilística y con cierta carga de subjetividad no obstante al esfuerzo que pueda realizar el examinador por no influir en las respuestas del sujeto.

- El mismo material puede encontrar aplicación en todos los grados de inteligencia del sujeto (Pardillo Palomino, J; Fernández Olazabal, P., 2001)

- En consecuencia, todo ello permite revelar las utilidades del método Rorschach en el proceso de enseńanza-aprendizaje, pues permite que el profesor realice el diagnóstico y la adecuación más efectiva, pues en lugar de considerar el estudiante promedio (estandarización positivista del proceso), realiza un estudio integral y personalizado del estudiante y planifica y ejecuta las actividades educativas según las características individuales y el nivel de desarrollo del aprendizaje de cada estudiante.

Ahora bien, entre otros beneficios importantes del método de Rorschach están:

- Permite realizar una evaluación integral, o proceso de caracterización sobre la personalidad del estudiante, sus potencialidades o debilidades, entendidas estas como inadaptación al entorno y exigencias del medio docente.

- Contribuye a la identificación de las dificultades en el desarrollo del aprendizaje de acuerdo a la etapa específica en la que se encuentra el estudiante.

- A su vez, permite determinar las principales áreas o esferas de conflictos de los estudiantes, en cuanto a la formación vocacional, motivaciones e intereses, posibles trastornos del aprendizaje, entre otras.

\section{El Rorschach como metodología de diagnóstico y transformación educativa}

Educar es depositar en cada hombre toda la obra humana que le ha antecedido: es hacer a cada hombre resumen del mundo viviente, hasta el día en que vive, es ponerlo a nivel de su tiempo, para que flote sobre él, y no dejarlo debajo de su tiempo, con lo que no podrá salir a flote. (MARTí, PÉrez J, 1976, pág. 114)

El método de Rorschach constituye una valiosa herramienta de trabajo educativo, porque permite la caracterización psico-pedagógica integral del estudiante, a partir de “... las aplicaciones de diferentes concepciones y teorias educativas para la resolución de un amplio espectro de problemas y situaciones referidos a la enseñanza y el aprendizaje, apoyadas en las Tics (tecnologías de información y comunicación)" (Dopazo Molina, E, 2015, pág. 3)

Por tanto, el Rorschach, al aprovechar las potencialidades de la informática y de las TICs, tiene la capacidad de estudiar y caracterizar de forma automatizada, acertada y verificable al estudiante en el contexto peculiar de la vida universitaria. Además, hoy el método se mantiene en constante evolución gracias a las nuevas y recientes investigaciones realizadas y a los aportes de los diferentes sistemas de codificación y evaluación, que también utilizan las tecnologías de avanzadas.

En concreto, en el método Rorschach se incluyen conocimientos tanto teóricos como empíricos, así como dispone de determinados medios e instrumentos de análisis, está dirigido al desarrollo de las capacidades y destrezas de los actores sociales involucrados, en este caso, del psicólogo, psicopedagogo y de los miembros del equipo de jueces y evaluadores, como vía más eficaz y consecuente de la aplicación del principio de reflexividad, en el cual, se exige atenuar el efecto del sesgo subjetivo de la información generado por la interpretación de los investigadores.

Además, en la investigación que sirve de base a este trabajo se elaboró un instrumento de diagnóstico para que los profesores perfeccionen el método de estudio de la personalidad de los estudiantes, el 
cual, gracias a su aplicación práctica, permitió identificar las siguientes dificultades esenciales (patrones muchas veces comunes para cualquier ámbito académico) en cuanto a la disposición y comportamiento de los estudiantes que comienzan las carreras de la educación superior:

\section{a) Déficit en los niveles de bienestar}

Entre los aspectos más esenciales en la teoría freudiana de las pulsiones sobresalen las ideas referidas al placer de la representación que debe imperar sobre la representación misma del órgano, así como el tema de la sublimación como conjugación del sentido personal y significación social de la actividad humana.

En este sentido Castoriadis sentenció:

"La ruptura con la animalidad está condicionada por el surgimiento de la imaginación radical de la psiquis singular y del imaginario social como fuente de las instituciones, vale decir de los objetos y actividades que pueden alimentar la sublimación. Ese surgimiento destruye la regulación «instintiva» de lo animal, le agrega al placer de órgano placer de representación, hace brotar la exigencia del sentido y la significación y le responde con la creación, a nivel colectivo, de las significaciones sociales imaginarias que dan cuenta de todo lo que pueda en cada caso presentársele a la sociedad considerada" (Castoriadis, C, 1998, pág. 5)

Estas ideas fueron compartidas también por Vigotski, quien sugiere que los profesores tomen seriamente en consideración lo positivo de los instintos variables, flexibles y libres de sus estudiantes, en concreto, el "placer de la representación" del estudiante (dimensión lúdica de la actividad), lo cual constituye el detonante que el profesor necesita desarrollar para elevar el interés y la motivación de sus discípulos por el aprendizaje.

Es decir, el arte del profesor de identificar ese "placer de la representación" del estudiante es la clave para potenciar la motivación y la creatividad, pues, mediante la facilitación de esas condiciones de placer en el quehacer cotidiano del estudiante, permite romper la rutina y el tedio y lograr la sinergia indispensable entre el significado social del aprendizaje y el sentido personal que tiene esa actividad para el estudiante.

Por último, el deseo de dominio del estudiante sobre el contenido y sobre el proceso mismo del aprendizaje también refuerza y hace más duradera tanto el interés como la motivación por el desarrollo creativo de esa actividad placentera.

\section{b) Inadaptación y desajuste psicológico del estudiantado al ambiente universitario}

Este aspecto ha sido ampliamente tratado en diferentes niveles de la educación en nuestro país enfatizando los investigadores en la necesidad de lograr un clima favorable al estudio y al trabajo donde los docentes y estudiantes sean protagónicos en el diseño del mismo" Y se agrega que... para organizar la vida de la escuela hay que tener en cuenta (entre otros aspectos) la creación de un ambiente adecuado en el que se desarrolle el proceso educativo" (MINED, 2003, pág. 36)

Algunos autores han enfatizado la necesidad de comprender el proceso de caracterización del estudiante como un proceso complejo, que supone una gran cantidad de dimensiones y aspectos de la vida del estudiante, así como reconocer que el diagnóstico es un componente específico de un subsistema mayor, relativo a los problemas más generales y significativos en el proceso de aprendizaje de los estudiantes, pues, con frecuencia: “... los estudiantes presentan serios problemas en su aprendizaje, lo que se manifiesta en bajo dominio de los contenidos que debieron vencer en años precedentes, insuficiente formación de las habilidades intelectuales, de su actividad reflexiva, de su motivación por el aprendizaje, poco desarrollo de sus responsabilidades y sus deberes, pobre formación de hábitos de estudio para lograr una 
preparación sistemática, asumiendo sin cuestionamiento lo enseñado por el profesor" (Velázquez Peña, E, 2006, pág. 9)

Sin embargo, la labor psico-pedagógica se ha podido identificar una serie de dificultades que afectan el proceso de diagnóstico de caracterización del estudiante universitario:

- En la práctica el estudio de caracterización es casi siempre psico-pedagógico, por lo que no se extiende a otras dimensiones también significativas para el estudio integral de la personalidad del estudiante (neurofisiológico, organizacional, sociológico, ético, artístico, entre otros)

- Además, el estudio de caracterización con frecuencia no enfatiza la dialéctica entre los aspectos cognitivos y afectivos (personológico) del proceso de aprendizaje de los estudiantes (González Collera, L, 1996, págs. 1-2)

- Todavía son pocas las investigaciones que estudian los intereses y motivaciones de los jóvenes y su impacto en el contexto del proceso de aprendizaje.

- Los profesores deben ser más creativos en el desarrollo de sus estrategias de enseñanza (Bonilla Vichot, I, 2005)

- En las diversas modalidades de la enseñanza en el nivel superior aún existen dificultades relacionadas con la utilización de adecuadas estrategias de aprendizaje, pocos estudiantes conocen y utilizan una estrategia propia, lo usual es realizar el aprendizaje independiente de forma repetitiva o reproductiva (memorística), atendiendo a las orientaciones del profesor, algo usual en el nivel precedente de enseñanza (Solís González, Y, 2004, pág. 70)

- Algunos estudiantes perciben el aprendizaje como una obligación y no como algo necesario para su desempeńo profesional y, a la vez, que puede constituir, en sí misma, una actividad placentera y recreativa que potencia el aprendizaje.

- Entre los estudiantes se percibe limitaciones en la auto-reflexión sobre el aprendizaje y pobre valoración crítica de lo realizado, ya que tienen limitaciones en las habilidades lógicas y metacognitivas de aprendizaje (Velázquez Peña, E, 2006, págs. 9-10)

\section{c) Aparición de conductas disruptivas dado el cambio de rutina y dinámica de la vida universitaria}

Es conocido en el ámbito académico de las ciencias psico-pedagógicas que los estudiantes en la entrada a la educación superior, regularmente, carecen de suficientes recursos adaptativos dada las limitaciones propias de la edad, así como a la falta de orientación vocacional adecuada. Ambos factores condicionan la dinámica personal de cada estudiante en la vida universitaria, provocando en ellos comportamientos incongruentes con las actividades sustantivas del nivel superior, que los conducen a disociarse y abandonar los objetivos de su formación académica.

En concreto, los estudiantes tienen dificultades con la adaptación rápida a las particularidades de la vida universitaria, que supone un cambio drástico de la rutina escolar precedente, pues ahora le exige elevar el nivel de responsabilidad personal y su real implicación en los procesos de construcción y transformación de su propia vida.

- Entre las conductas disruptivas más representativas de esta etapa de la vida estudiantil se destacan:

- Ausencias reiteradas y sin justificación a clases.

- Desinterés o desmotivación por el estudio.

- Insatisfacción personal que finalmente se puede traducir en frustraciones o conflictos, que impactan en el rendimiento académico.

d) Cambios cualitativos en las relaciones inter-personales.

El proceso del aprendizaje humano tiene su basamento en la esfera cognoscitiva fundamentalmente, (sin que estemos sub-valorando el potencial de la esfera afectiva como inductora y motivadora de ésta 
actividad), asociado a complejas funciones psíquicas como son los procesos perceptivos, atención, memoria, pensamiento, entre otros, donde el individuo se va apropiando paulatinamente del conocimiento y de la experiencia histórico-social en determinada esfera del saber o área del conocimiento. Este proceso surge y se desarrolla en un contexto social determinado y en conjunto con los profesores y demás estudiantes, en el cual el individuo puede ir aplicando dichos conocimientos en la medida en que se apropia de este.

Algunas dificultades identificadas en este aspecto interpersonal son:

- Tendencia al aislamiento, o pobre integración a las actividades grupales.

- Irritabilidad.

- Comunicación pobre o limitada al aspecto profesional y docente.

- Escasa percepción de sus principales dificultades o carencias en esta esfera, condición que dificulta la satisfacción de las necesidades o resolución de conflictos.

\section{e) Apatía hacia las actividades de la vida universitaria.}

La apatía es un estado afectivo-volitivo del estudiante, asociado a la falta de interés o de la disminución de la energía física y psicológica implicada hacia la actividad docente, que, a su vez, genera en el estudiante despreocupación por el estudio. Dicho estado, si se prolonga demasiado tiempo, trae aparejadas consecuencias muy negativas que finalmente pueden llevar al abandono de los estudios, con todas las frustraciones personales que esto trae aparejado.

En consecuencia, un verdadero estudio de diagnóstico de las particularidades psicológicas del estudiante debe enfatizar la dimensión motivacional o personológica, como una de las premisas esenciales para el desarrollo del proceso de aprendizaje de los estudiantes (González Collera, L, 1996, págs. 1-2)

\section{f) Disminución de los niveles de tolerancia a situaciones estresantes}

Este aspecto está estrechamente relacionado con los recursos de afrontamiento de la personalidad con los que cuenta el individuo, para adaptarse de forma práctica y viable en determinado contexto, en este caso al ámbito docente.

El aumento de las tensiones provocadas por la dinámica propia de la vida universitaria, unidas a las exigencias que impone la cotidianeidad, pueden ser factores que faciliten la aparición de emociones negativas en los estudiantes, tales como:

- Malestar.

- Disforia.

- Insatisfacción o inconformidad.

- Estados patológicos como: ansiedad y depresión, entre otros.

\section{g) Trastornos del aprendizaje}

Entre las dificultades más significativas que presentan los estudiantes en el proceso de aprendizaje están las siguientes:

- Pobre formación de hábitos de lectura y de estudio para lograr una preparación sistemática.

- Insuficiente formación de habilidades intelectuales, tales como: pensamiento reflexivo y crítico, operaciones lógicas de comparación, análisis, síntesis, generalización y abstracción (De Bono, Edward, 1980), (Kopnin, P.V., 1980), (Rodríguez Ugidos, Zaira, 1986), (Agramonte Rosell, Regina, 2003), (Bonilla Vichot, I, 2005), (Velázquez Peña, E, 2006)

Con frecuencia, la mayoría de los estudiantes asume, sin cuestionamientos, lo enseñado por el profesor, en lugar de ser más crítico y problematizador en el diálogo con el educador. Es decir, el estudiante debe tener en cuenta la importancia didáctica y ética del denominado "idolo del teatro" de 
Francis Bacón, así como el valor epistemológico del principio del "escepticismo organizado" de Robert Merton, el cual constituye uno de los principios éticos de la ciencia: 1) Comunismo, 2) Universalismo, 3) Desinterés, 4) Escepticismo organizado, (Núñez Jover, J., 1999, págs. 92-98)

Además, en lo relativo a los trastornos del aprendizaje, se debe partir de su comprensión como un deterioro de las formas normales de aprendizaje, es decir, no solo como consecuencia de dificultades en las relaciones sociales o por la falta de oportunidad para aprender, sino como un déficit en los procesos cognoscitivos que dificultan la asimilación del contenido. De hecho, las causas son múltiples, entre ellas se destacan:

- Dificultades biológicas.

- Alteraciones psicológicas de los procesos cognoscitivos, afectivos o de la personalidad en general que afectan el desarrollo del sujeto.

- Consecuencias de psico-traumas o procesos adquiridos, entre otros.

Así también, en las tendencias y patrones anteriormente identificados se pueden determinar otras dificultades y profundizar en las ya detectadas a partir del método Rorschach, tales como: el tipo de dificultad, sus características, la influencia en la actividad cognoscitiva del sujeto y la implicación de los procesos cognoscitivos y afectivos, así como el posible sustrato orgánico de la dificultad identificada.

\section{h) Otras dificultades en el orden docente}

Se ha podido constatar que, en el plano actitudinal, algunos estudiantes evidencian poco desarrollo de sus responsabilidades y deberes académicos en el ámbito universitario (dimensión ética), en especial, ante las actividades de estudio.

En cuanto a otras dificultades en el orden docente se describen otros trastornos que bloquean o afectan en alguna medida el aprendizaje en el nivel superior de enseńanza, aun en presencia de procesos cognoscitivos conservados en lo esencial y sin daño biológico aparente.

En este caso se destacan los trastornos afectivos y los trastornos de la conducta, como elementos desorganizadores de la actividad cognoscitiva del sujeto, al fallar en el primer caso los mecanismos reguladores inductores y activadores de la ejecución cognitiva, en el segundo caso se afecta la interacción del sujeto con el entorno, al ser disfuncionales sus recursos de interacción, siendo posible identificar todos los elementos descritos anteriormente a través del método de Rorschach.

Aquí radica otra de las utilidades del método Rorschach en el proceso de enseñanza-aprendizaje, pues permite que el profesor realice la adecuación más efectiva, no solo considerando el estudiante promedio, sino más que todo personalizando las actividades educativas según las características individuales y el nivel de desarrollo del aprendizaje de cada estudiante.

A su vez, el método Rorschach tiene un valor muy especial como técnica e instrumento de contrastación empírica de carácter pre-experimental de confirmación o refutación de hipótesis propiamente sociales, mediante el cual se verifica el grado de transformación inducida por la propuesta implementada.

\section{Valor práctico del diagnóstico psico-pedagógico del Rorschach como metodología para la transformación del estudiante}

Además, de los objetivos del psico-diagnóstico de Rorschach es preciso resaltar la finalidad de su aplicación, pues se constituye en una herramienta muy valiosa para el tratamiento profiláctico o terapéutico de la situación del estudiante, mediante un plan de actividades creativas para su transformación en los planos preventivo y compensatorio. 
En consecuencia, para la aplicación de la metodología del Rorschach, en estas dos complejas áreas de transformación de la personalidad del estudiante, es preciso considerar una serie de dimensiones psicológicas:

1) Actividad cognoscitiva: se refiere a los aspectos cognoscitivos de la personalidad, la manera en que cada estudiante aborda, ejecuta e integra sus respuestas, por lo que remite a la capacidad de utilizar los procesos lógicos del pensamiento, tales como: comparación, analogía, diferenciación, análisis, sintesis y generalización (Exner, J.; Sendín,C., 1998) Estos autores la conciben y conceptualizan como tríada cognitiva, la cual está formada por 1) el procesamiento de la información, 2) la mediación cognitiva y 3) el proceso de ideación.

2) Afectividad: el análisis de los afectos se encuentra muy unido con las cogniciones del estudiante (principio vigotskiano de la unidad dialéctica entre lo cognitivo y lo afectivo), pues los afectos y emociones inducen e incentivan la realización de sus actividades como vía para satisfacer las necesidades, intereses y objetivos. El método aporta información valiosa del papel de lo afectivo en la actividad cognoscitiva de la personalidad, sus reacciones emocionales, el manejo de los afectos y en qué medida estos han impactado en la toma de decisiones y en las interacciones estudiante con el complejo entorno social (micro la familia, meso la comunidad y el macro relativo a la localidad, provincia y nación). ${ }^{26}$ Entre las nociones esenciales de la esfera afectiva se destacan las motivaciones (intrínsecas y extrínsecas), intereses, estados de ánimo, afectos, sentimientos, conflictos, auto-percepción, auto-valoración, auto-estima, objetivos, expectativas, etc.

El análisis de las emociones y sentimientos del individuo con el método es decisivo, porque es la esfera afectiva el factor que induce, orienta, motiva y regula el comportamiento del estudiante hacia determinada tarea. Por tanto, es de vital importancia considerar la verdadera implicación de cada estudiante en la actividad, es decir, si reconoce sus emociones para poder regularlas en función de la interacción con el medio social, lo que en términos de la inteligencia emocional se denomina manejo adecuado y adaptativo (resiliente) de las emociones propias y ajenas (Goleman, D, 1995), (Goleman, D, 1999)

Por ejemplo, el estudiante que tenga un adecuado autoconocimiento y autocontrol de sus emociones, evidencia equilibrio emocional, lo que le permite afrontar con éxitos los problemas de aprendizaje, mediante el mejoramiento de sus recursos cognitivos propios y el adecuado manejo de las relaciones con sus profesores, compañeros del grupo de clase, en el seno familiar y en la comunidad, es decir, de todas sus relaciones en el contexto social.

3) Particularidades vivenciales (tipo vivencial): nos informa del tipo de relaciones que se establecen en cada sujeto en cuanto a las dimensiones cognitiva y afectiva, es decir, permite identificar qué características tienen las vivencias del sujeto en lo relativo a ambos componentes.

La determinación de la dimensión relativa a las particularidades de las vivencias del individuo, denominado tipo vivencial, estuvo marcada por las ideas de Dilthey, ${ }^{27}$ quien se opuso al reduccio-

26 Es preciso esclarecer la relación entre las escalas del entorno, así el uso de otros términos como contexto, el cual remite a la descripción concreta de las peculiaridades del entorno de un sistema dado, por ejemplo, de un trabajo científico, de una obra de arte, de un método, etc. Por ejemplo, la aplicación de este principio del análisis del contexto histórico-concreto permite describir el proceso de creación del propio método Rorschach en el ámbito de la medicina, específicamente, en la psiquiatría en las primeras dos décadas del siglo XX. Además, el propio principio posibilita revelar, que el surgimiento del término "esquizofrenia", estuvo estrechamente vinculado al desarrollo de los estudios sobre esta enfermedad, pues el creador de este término fue Eugen Bleuler profesor y compañero de Rorschach. Además, Bleuler supervisaba las investigaciones doctorales de Rorschach acerca de las alucinaciones.

27 Wilhelm Dilthey (1833-1911) fundamenta el significado del aspecto psicológico (subjetivo) en el conocimiento (en la misma línea de las ideas de Protágoras, Aristóteles, Montaigne, Vico, Hume, Kant, Hegel y del Marxismo), además, enfatizaron la necesidad de reconocer que el conocimiento científico social implica presuponer el estudio de la esfera espiritual, de los pensamientos, sentimientos y motivos que guían la conducta de los hombres que son objeto de la investigación (Dilthey, Wilhelm, 1900/1976). En verdad, Dilthey con su Hermenéutica metódica y siguiendo esa pista aportada por el 
nismo impuesto por la aplicación irracional del método de las ciencias naturales al ámbito de las ciencias sociales y humanísticas (Dilthey, Wilhelm, 1900/1976)

El tipo vivencial o "erlebnistypus" (EB) del Rorschach es esencial para comprender también las características del pensamiento y sus procesos en relación con la toma de decisiones de cada sujeto, lo que permite en alguna medida prever alguno de los comportamientos o actitudes de los individuos ante determinadas situaciones porque el EB es relativamente estable y representa los estilos habituales de respuesta ante determinada situación.

En concreto, Rorschach sugiere la caracterización de cada sujeto en una de las siguientes categorías, las cuales pueden ser aplicables a la identificación de los rasgos distintivos de la personalidad de los estudiantes, tales como:

a) Introversivo: ${ }^{28}$ se asocia a personas que prefieren analizar todas las posibles alternativas ante las situaciones con las que interactúan, prefiriendo utilizar la lógica de forma precisa y que evite complicaciones. Este tipo vivencial representa a los individuos básicamente ideacionales, con gran control de sus emociones en el proceso de resolución de problemas, quienes formulan sus juicios, a partir de la evaluación interna, por lo que prefieren evaluar todas las posibles alternativas antes de tomar una decisión.

Además, su inteligencia tiende a ser normal o brillante, su vida interior es muy rica, pero con dificultades para adaptarse fácilmente a la interacción social. En ocasiones, el tipo vivencial está rigidificado, lo cual indica que el individuo presenta un estado de ensimismamiento que tipifica el "vivir para sí".

b) Extratensivo: predomina en sujetos emocionales que mezclan sus afectos con su pensamiento en la tarea de resolución de problemas, así como sus juicios se encuentran influenciados por la información proveniente del exterior, es decir, del medio social, el cual es fuente de gratificación para ellos, quienes, por tanto, prefieren utilizar el "ensayo-error" como método para dar solución a sus problemas. Además, se caracterizan por ser individuos con mayores habilidades para la vida social, así como evidencian mayor desarrollo en su desempeńo cotidiano, sin embargo, con frecuencia son más vulnerables al descontrol afectivo.

c) Coartado: ${ }^{29}$ este tipo vivencial caracteriza a los sujetos que parecen estar paralizados afectivamente, quienes están a la defensiva para protegerse de los estímulos perturbadores del entorno, pero, al no disponer de recursos accesibles suficientes para organizar su conducta, quedan vulnerables ante las tensiones del medio social. Las personas de este tipo vivencial funcionan relativamente bien en un clima psicológico favorable, pero al ocurrir eventos tensos y generadores de estrés se desestabilizan afectiva y conductualmente.

d) Ambigual: se asocia a personas más inseguras, vacilantes que usualmente necesitan más tiempo para realizar sus tareas, ante la toma de decisiones es voluble o inconsecuente, en detrimento de su coherencia interna. Los sujetos ambiguales tienden a ser imprevisibles en su conducta, debido a que, en ocasiones, su pensamiento es muy irregular e irreflexivo, por las influencias de sus emociones y sentimientos en las tareas de resolución de problemas. Por tanto, son personas que tienden a correr mucho riesgo en la tomar decisiones.

historiador alemán Johann Gustav Droysen (1808-1884), ayudó a esclarecer este problema: "Por oposición a las ciencias de la naturaleza, cuyo modo de conocer los fenómenos naturales es la explicación, Dilthey vio en la comprensión el método propio de las ciencias del espiritu, cuyo objeto abarca la totalidad de los fenómenos humanos" (Fortes Sánchez, Alberto, 2001, pág. 4) Nótese la sutil diferencia con el término introvertido, que remite a una persona con rasgos comportamentales similares, pero en el caso del introversivo, como tipo vivencial, se refiere a las relaciones del sujeto con su medio social.

29 Para otras escuelas, como la de Bruno Klopfer, se considera además el tipo vivencial coartativo. Las personas de este tipo vivencial tienden al vivir neurótico con fuertes elementos obsesivos en la conformación psicológica de su personalidad, son muy rígidas afectivamente, poco adaptables y con baja capacidad receptiva a la labor psicoterapéutica. 
En esencia, esta clasificación revela las características distintivas de la vida psíquica de cada discente. De manera que su aplicación, en el ámbito docente, les puede proporcionar a los profesores y directivos escolares una valiosísima información de la personalidad de cada estudiante. En consecuencia, se podrán planificar nuevas, más efectivas y creativas estrategias para elevar la calidad del aprendizaje de los estudiantes, ya que se podrán orientar las estrategias personalizadas en función de la solución de los problemas identificado en cada estudiante.

Además, el profesor siempre debe tener presente que el aprendizaje del estudiante es un proceso complejo de significaciones sociales y personales, que exige tanto el esfuerzo, el interés y la motivación personal, como la actividad cooperada y solidaria de la ayuda del "otro", es decir, del profesor, del adulto o del compañero de clase, lo que constituye, según la concepción vigotskiana, la premisa indispensable para el desarrollo de la auto-ayuda (Vigotski, L.S., 1991)

Precisamente, las mejores tradiciones psico-pedagógicas, así como los estudios de la complejidad, han enfatizado los conceptos de:

"Auto-conciencia, auto-aprendizaje, metacognición, auto-valoración y pensamiento autónomo, que son, entre otras, ideas esenciales de la tradición iniciada por L.S. Vigotsky, la cual subraya la necesidad de potenciar la ayuda de los "otros" para generar la posibilidad de la auto-ayuda, lo que tiene ... un revolucionario valor para el desarrollo del educando y del colectivo, es decir, urge aprovechar sus potencialidades creativas y orientar sus valiosas energías hacia la imaginación, la innovación y la auto-organización del colectivo. "(Martínez Álvarez, F., 2000, págs. 106-107)

De hecho, para cada estudiante algo es significativo cuando lleva impreso el sello personal, es decir, la importancia que tiene en relación a la satisfacción de alguna necesidad, interés o expectativa del estudiante.

Desde la interpretación de la clasificación de la personalidad que sugiere el método de Rorschach, algunos estudiantes son más reflexivos y analizan cada aspecto de la realidad para tomar cuidadosamente una decisión; otros, por el contrario, se dejan llevar más por sus percepciones y emociones, por lo que son más apasionados en el desarrollo de sus actividades; mientras que otros pueden asumir posiciones intermedias y restringen al máximo tanto las emociones como los conocimientos de la realidad para tomar una decisión concreta (Martínez Miguélez, M, 1997)

4) Auto-percepción: es la capacidad de cada individuo para auto-analizarse y comprenderse, mediante la identificación de sus propias cualidades personales (aptitudes, hábitos, conocimientos, habilidades, destrezas, capacidades, actitudes, sentimientos, emociones, memoria, intuición y valores), es decir, la auto-percepción tiene una influencia directa en su autoimagen, auto-valoración y auto-estima. Por tanto, la auto-percepción del estudiante constituye una síntesis valorativa de sí, de aspectos tanto cognitivos como afectivos relacionados con la comprensión integral y sistemática de sí mismo.

Además, un concepto relativamente reciente y que guarda estrecha relación con los aspectos incluidos en la auto-percepción, es la noción de inteligencia emocional, ${ }^{30}$ acuñado por Salovey y Mayer, quienes sentencian que la Inteligencia emocional constituye la «... habilidad para manejar los sentimientos y emociones propios y de los demás, de discriminar entre ellos y de utilizar esta información para guiar el pensamiento y la acción de uno mismo» (Salovey, P. \& Mayer, J.D., 1990, pág. 189)

30 Más adelante se volverá sobre la teoría de la inteligencia emocional (Salovey, P. \& Mayer, J.D., 1990), (Goleman, D, 1995), ya que juega un papel muy importante en el desarrollo de una concepción integral, activa y creativa de la enseńanza por el profesor, así como para el fomento de la motivación del aprendizaje de los estudiantes. 
Ahora bien, la concepción de Inteligencia emocional que propone Goleman, profundiza más en cuanto a su aspecto didáctico, ya que exige al profesor orientar al estudiante la realización consecuente del auto-diagnóstico, como premisa indispensable para poder desarrollar sus dos aspectos principales y la interrelación dialéctica entre ellos:

a) La inteligencia intra-personal, que constituye la aptitud emocional, la capacidad de conocerse y de controlar las emociones propias, y que está compuesta por las cualidades de auto-conciencia, auto-conocimiento, auto-regulación, auto-control, auto-determinación y motivación.

b) La inteligencia inter-personal, que posibilita percibir los estados de ánimo, motivaciones e intenciones de los demás, aunque estas no sean tan evidentes, por lo que sugiere la necesidad de fomentar y desarrollar esta inteligencia en maestros, profesores, líderes religiosos, directivos, terapeutas y padres (Goleman, D, 1995)

En verdad, la labor del profesor debe estar dirigida a fomentar en los estudiantes la capacidad de auto-diagnosticarse, es decir, revelar la riqueza y complejidades de su inteligencia intrapersonal, la cual implica el complejo proceso de auto-conocimiento y auto-valoración, que, a la vez, permite el acceso a su propia vida emocional, sentimientos, motivaciones y pasiones más íntimas (introspección). De manera que, no solo el propio estudiante, sino también el profesor pueda identificar y recurrir a esos elementos de la personalidad como medio para orientar la conducta de cada estudiante.

5) Relaciones inter-personales: se asocia con la capacidad del estudiante para las relaciones colectivas y sociales, su forma particular para establecerlas y mantenerlas, la imagen de los demás compañeros y su relación con la propia, aunque no deja de tener también estrecha relación con las ideas y nociones de la inteligencia intra-personal, las cuales determinan el conocimiento de uno mismo, algo esencial para poder afrontar los problemas inherentes a las relaciones colectivas y sociales.

Estas dos inteligencias (intra e inter) son significativas para el individuo y sus relaciones sociales, pues la inteligencia inter-personal permite a cada estudiante comprender y tratar asertivamente con colegas y amigos. Por tanto, es de vital importancia el riguroso adiestramiento de los profesores para la identificación de las particularidades de cada tipo de manifestación de las emociones en cada estudiante.

En ese sentido, Goleman expresó que: "Quisiera imaginar que, algún día, la educación incluirá en su programa de estudios la enseñanza de habilidades tan esencialmente humanas como el autoconocimiento, el auto-control, la empatía y el arte de escuchar, resolver conflictos y colaborar con los demás" (Goleman, D, 1995, pág. 7)

Entre las razones por las cuales Goleman enfatiza la importancia de la inteligencia inter-personal, está el hecho de que este tipo de inteligencia remite a la necesidad de desarrollar en cada estudiante una actitud social, de espíritu colectivista, es decir, que todo estudiante debe desarrollar cualidades personales tan importantes como son la empatía comunicacional y las habilidades en el manejo de las emociones de otros con el fin de propiciar las relaciones colectivas y sociales.

Por empatía comunicacional se asume aquí la capacidad del individuo de aceptar y comprender al interlocutor, saber ponerse en la posición del otro, saber escuchar, facilitar un clima psicológico de confianza $\boldsymbol{\text { mutua }},{ }^{31}$ colaboración y aporte de información, es decir, hay empatía cuando existen y se fomentan intereses y motivaciones comunes, cuando se muestra interés mediante

31 En la noción de confianza mutua significa también aceptar la legitimidad de las circunstancias y razones del otro y la propia. 
preguntas apropiadas y la participación activa, lo que es favorable para el diálogo productivo, que genera respeto y afecto por las ideas y el comportamiento del otro.

Además, empatía significa aceptar y afrontar las diferencias de los demás con el objetivo de alcanzar una comunicación plena con el interlocutor, sea profesor o estudiante. Así también, para lograr alta empatía comunicacional es preciso desarrollar una comunidad de lenguaje, tanto verbal como extra-verbal (gestual-corporal y simbólico), como vía más eficaz para que tanto el profesor como el estudiante logren alcanzar una adecuada adaptación o resiliencia ${ }^{32}$ al medio educativo y social, la cual garantiza la robustez adaptativa que conlleva la sustentabilidad de todas sus labores escolares y extracurriculares.

6) Mecanismos de afrontamiento, control y tolerancia al estrés: Se refiere a las cualidades y recursos que tiene el estudiante para manejar las situaciones estresantes, mediante la autoconsciencia del proceso de búsqueda de soluciones a los problemas sin enfrentarse a ellos, sino buscando los medios y vías para la resiliencia como adaptación creativa ante las perturbaciones del entorno social, es decir, en aquellos enclaves fuera de la vida escolar, tales como: familia, vecindario, comunidad, localidad, región, etc.

Además, estos mecanismos son recursos de la personalidad tanto en el plano cognitivo como afectivo, que pueden permitir el desarrollo meta-cognitivo y consciente de la auto-organización del proceso de adaptación del estudiante, mediante la ayuda del otro: familiares y amigos cercanos o especialistas, proceso este que le permite a cada estudiante encontrar las soluciones pertinentes y eficaces a los problemas que se le presentan en el proceso docente, aprovechar la influencia positivas de las actividades extracurriculares; todo lo cual supone también la reorientación de su conducta hacia la auto-transformación positiva para el bien personal y colectivo.

Desde el punto de vista etimológico, afrontar proviene del latín affrontare, frons, frontis, poner cara a los recursos, los problemas y las posibilidades, hacer frente a un desafío, peligro, o crisis. Sin embargo, la evolución lógica y psicológica del término le ha dado un giro semántico hacia la comprensión opuesta, es decir, la nueva noción, desde la perspectiva de las ideas de la complejidad, asume el significado de "a-frontar" como no-enfrentar, o no hacer frente, sino asumir una actitud reflexiva ante los problemas no de enfrentamiento, sino de adecuación adaptativa o resiliencia fundada (Fried Schnitman, D, 2005), (Fried Schnitman, D, 2011), (Fried Schnitman, Dora y Mario Rodriguez-Mena García, 2011)

Ahora bien, en el proceso de afrontamiento de conflictos, según la concepción de Rorschach, se deben valorar fundamentalmente dos aspectos:

a) Uno más situacional, usualmente provocado por un evento o noxa ambiental (entendida esta como algo que ocurre inesperadamente) y que puede sobrepasar el umbral de tolerancia a situaciones estresantes del estudiante.

b) Otro que perdura o permanece por largos períodos en el tiempo de acuerdo a la situación particular de cada estudiante y a sus potencialidades.

32 Resiliencia: es un término nacido en la metalurgia (como estrés) para referirse a la capacidad de los metales para soportar alta temperatura, presión, oxidación o humedad. Luego se convirtió en una noción transdisciplinaria, pues ha sido acogido en las ciencias sociales con el significado de la capacidad de adaptación rápida de las personas a las perturbaciones del entorno social, en concreto, en psicología se refiere a la capacidad del sujeto de sobreponerse a períodos de dolor emocional y situaciones adversas (pérdida de un ser querido por muerte o separación). De hecho, entre los estudiosos de la complejidad se habla ya de teoría de la resiliencia, así como el término ha tenido aceptación en psicología, psiquiatría, pedagogía, dirección organizacional, sociología, ecología, entre otras áreas de las ciencias sociales y las humanidades. En sociología la resiliencia en comprendida como la capacidad de los grupos sociales de sobreponerse a los resultados adversos, reconstruyendo sus vínculos internos (auto-organización) a fin de hacer prevalecer su homeostasis colectiva (equilibrio dinámico del sistema con el entorno), de modo tal que no fracase en su propia sinergia. 
Tales condiciones y situaciones psicológicas complejas afectan la calidad de vida de los estudiantes adolescentes y su adaptación al medio escolar, así como limita sus recursos de afrontamiento de los conflictos propios del proceso de aprendizaje, lo que repercute negativamente sobre el proceso personal y colectivo. De manera que es preciso que los profesores fomenten y desarrollen en los estudiantes nuevas habilidades adaptativas, de las cuales carecían hasta ese momento.

En fin, el desarrollo de nuevos mecanismos de afrontamiento implica que los estudiantes potencien sus habilidades para elevar la empatía comunicacional, las capacidades de reorientar las emociones propias, la focalización en los objetivos y metas personales y colectivas, así como encontrar, con la ayuda de sus colegas, amigos y familiares, nuevas alternativas y posibilidades de elevar el nivel de motivación por el aprendizaje. En ello juega un papel primordial el modelado y la socialización de las lecciones aprendidas, ambos procesos entendidos como re-aprendizaje colectivo.

\section{CONCLUSIONES}

Los fundamentos teóricos del Rorschach como método psico-diagnóstico de la personalidad aparecieron como resultado de la evolución y articulación espontánea de varias disciplinas y áreas de conocimientos, entre las que están: psicología experimental, diferencial, aplicada, en especial, la relativa a los test de caracterización y evaluación de la personalidad como expresión de las demandas sociales y exigencias del estudio de las enfermedades mentales (esquizofrenia), de las particularidades psicológicas de las personas para el empleo en el ámbito industrial y militar.

El método de Rorschach tiene un especial valor social y gran utilidad práctica que se revela en diferentes esferas de actuación y áreas del conocimiento, entre las cuales están: la psicología clínica o de la salud, la psiquiatría infantil, general, forense, la investigación socio-cultural (antropológica y etnográfica), la dirección y psicología organizacional, así como en la labor psico-pedagógica o educativa.

El valor metodológico del Rorschach, como tecnología de transformación psico-educativa de los estudiantes, se expresa en el ámbito pedagógico, pues brinda una aproximación muy acertada del nivel intelectual de cada estudiante, así como permite revelar las potencialidades o debilidades del educando en la vida estudiantil, porque contribuye a la identificación de las áreas o esferas de conflictos, motivaciones e intereses, posibles trastornos del aprendizaje, todo lo cual sirve de base al profesor y el colectivo pedagógico, para el ulterior proceso de transformación educativa de los estudiantes.

\section{REFERENCIAS BIBLIOGRÁFICAS}

Agramonte Rosell, Regina. (2003). Una estrategia para la comprensión lectora basada en la estimulación del aprendizaje reflexivo. Disponible en: http://www.palermo.edu.ar/facultadesescuelas/ dyc/cestud/refl_acad/tyh_01_jornadas_2004/ zentneraprendizaje.htm.

Alonso, A.; et. al. (2003). Psicodiagnóstico. Selección de Lecturas. La Habana: Félix Varela.

Bonilla Vichot, I. (2005). Las estrategias de aprendizaje y su relación con el rendimiento académico en alumnos de preuniversitario. Tesis de Maestría. La Habana: Universidad de la Habana. Facultad de Psicología.

Canfux Sanler, Verónica; González Pacheco, Otmara; et. al. (1995). Los métodos participativos ¿una nueva concepción de la enseñanza? La Habana: CEPES.

Castoriadis, C. (1998). Pasión y conocimiento. El amor por la verdad. Revista Zona Erógena. No. 37.

Corral Ruso, R. (2003). Historia de la psicología. Apuntes para su estudio. La Habana: Félix Varela. 
De Armas Ramirez Nerely. (2003). Caracterización y diseño de los resultados científicos como aportes a la investigación Educativa, ponencia, Pedagogía. Revista de Ciencias Médicas, La Habana.

De Bono, Edward. (1980). El pensamiento lateral. Manual de creatividad. Barcelona: Editorial Paidós.

Dilthey, Wilhelm. (1900/1976). The rise of hermeneutics. En P. Connerton, Critical sociology. New York: Penguin.

Escobar, Javier. (2010). El Método de Rorschach. El Sistema Comprehensivo de John Exner. Conferencias. Sevilla: Universidad de Sevilla.

Esquijarosa Chirino R., et al. ( 2014). Estrategia de superación para profesores que imparten docencia en la carrera de Tecnología de la Salud. Revista de Ciencias Médicas, 3-4.

Exner, J. (1994). El Rorschach. Un Sistema Comprehensivo. Volumen 1: Fundamentos básicos. Madrid: Psimática.

Exner, J.; Sendín,C. (1998). Manual de Interpretación del Rorschach para el Sistema Comprehensivo. Madrid: Psimática.

Fernández Olazabal, P.; Pardillo Palomino, J. (2008). Sistema Integrador explicativo del Rorschach. La Habana: Editorial Edcimed.

Fernández Olazabal, Pedro. (2004). Normas para la calificación e interpretación del psicodiagnóstico de Rorschach en tres grupos poblacionales cubanos. Tesis de Doctorado. La Habana: Universidad de la Habana.

Fiallo Rodríguez, Jorge. (2003). ¿Cómo formar pensamiento interdisciplinario en la escuela? La Habana: Pueblo y Educación.

Fortes Sánchez, Alberto. (2001). Filosofía y teoría de la ciencia en Gadamer.

Fried Schnitman, D. (2005). Afrontamiento de crisis y conflictos: una perspectiva generativa. Sistemas Familiares.(21(1-2)), 98-118.

Fried Schnitman, D. (2011). Afrontamiento generativo de crisis y conflictos en organizaciones. Revista Persona(14), 11-40.

Fried Schnitman, Dora y Mario Rodriguez-Mena García. (2011). Afrontamiento generativo y desarrollo comunitario. En J. F. García Rodríguez, J. Betancourt Bethencourt, \& F. Martínez Álvarez, Transdisciplina y desarrollo humano. (págs. 256-287). México: Editorial Dirección de Calidad y Enseñanza en Salud de la Secretaría de Salud del Estado de Tabasco.

García Gutiérrez, Alberto. (2005). Metodología para contribuir al perfeccionamiento del ambiente pedagógico en la secundaria básica. Villa Clara: Instituto Superior Pedagógico "Félix Varela y Morales.

Goleman, D. (1995). Inteligencia emocional. México: Javier Vergara Editor.

Goleman, D. (1999). Inteligencia social. México: Javier Vergara Editor.

González Collera, L. (1996). Motivación humana. Una alternativa para su estudio en jóvenes y adolescentes. Tesis de Maestría en Educación. La Habana: Instituto Pedagógico Latinoamericano y Caribeño (IPLAC).

González Maura, Viviana; Castellano Simons, Doris. (1995). Psicología para educadores. Ciudad de La Habana, Cuba: Editorial Pueblo y Educación.

González Soca, Ana María. (2002). El diagnóstico pedagógico integral. En A. M. González Soca, \& C. Reinoso Cápiro, Nociones de sociología, psicología y pedagogía. (págs. 72-89). La Habana: Pueblo y Educación.

Hawking S. (10 de Diciembre de 2017). Cursor de 2017. Juventud Rebelde, pág. 5.

Kopnin, P.V. (1980). Lógica dialéctica. La Habana: Editorial Pueblo y Educación.

López Angulo, L. (2010). Compendio de Instrumentos de Evaluación Psicológica. La Habana.: Ecimed. López Vázquez, A. (2015). El Test de Rorschach condiciones de normalización. Tesis para optar al grado de magister en psicología. Chile: Universidad. 
Martí, Pérez. J. (1976). Escritos sobre educación. La Habana: Ciencias Sociales, Instituito cubano del libro.

Martínez Álvarez, F. (2000). La visión social de la Tecnociencia en Cuba. Universidad de la Habana, Dirección de Postgrado. La Habana: Dirección de Postgrado de la Universidad de La Habana.

Martínez Álvarez, Fidel. (2011). Fundamentos epistemológicos para la construcción de una Educación transdisciplinaria en Cuba. Tesis de Doctorado. La Habana: Centro de Perfeccionamiento de la Educación Superior de la Universidad de la Habana. En: http://revistas.mes.edu.cu/ greenstone/ collect/repo/index/assoc/ D9789591/618771.dir/9789591618771.pdf.

Martínez Miguélez, M. (1997). El paradigma emergente: hacia una nueva teoría de la racionalidad cientifica. México: Editorial Trillas.

Martínez Miguélez, M. (1996). Comportamiento Humano: Nuevos métodos de investigación. México: Editorial Trillas.

Maturana, H; Varela, F. (1971/1995). De máquinas y seres vivos. Autopoiesis. La organización de lo vivo. Santiago de Chile: Editorial Universitaria.

MINED. (2003). La escuela como micro-universidad en la formación integral de los estudiantes de carreras pedagógicas. La Habana: Pueblo y Educación.

Núñez Jover, J. (1999). La ciencia y la tecnología como proceso sociales. La Habana, Cuba: Félix Varela.

Pacey, A. (1990). La cultura de la tecnología. México: Fondo de Cultura Económica.

Pardillo Palomino, J. (2004). Psicodiagnóstico de Rorschach. Sistematización de resultados en diferentes contextos de aplicación. Tesis de Doctorado. La Habana: Universidad de la Habana.

Pardillo Palomino, J; Fernández Olazabal, P. (2001). Psicodiagnóstico de Rorschach. Un Manual para la Práctica. Camagüey: Editorial Ácana.

Platón. (1972). Obras completas. Diálogos. Fedro. Madrid: Aguilar.

Robert, Marthe. (1967). La revolución Psicoanálitica. La vida y obra de Freud. La Habana: Instituto del Libro.

Rodríguez Ugidos, Zaira. (1986). Problemas de la lógica dialéctica. La Habana: Editorial Pueblo y Educación.

Rorschach, Herman. (1966). Psicodiagnóstico. La Habana: Revolucionaria.

Salovey, P. \& Mayer, J.D. (1990). Emotional intelligence. Imagination, Cognition and Personality. Vol. 9, N. 3, 185-211.

Solís González, Y. (2004). Propuesta Didáctica para el desarrollo de estrategias de aprendizaje con el apoyo de las Tecnologías de la Información y las Comunicaciones. Tesis doctoral. La Habana: CUJAE.

Velázquez Peña, E. (2006). Estrategia didáctica para estimular el aprendizaje reflexivo en los estudiantes de las carreras de ciencias naturales de los institutos superiores pedagógicos. Tesis de doctorado. Camagüey: Instituto Superior Pedagógico “José Marti”" de Camagüey.

Vigotski, L.S. (1991). Pensamiento y lenguaje. Obras Esogidas. Tomo 2. Madrid: Visor Libros.

Vigotsky, L.S. (1916/1972). Psicología del Arte. Tomo I. Barcelona: Barral Editores.

Vigotsky, L.S. (1924/2000). Psicología Pedagógica. Un curso breve. Buenos Aires: Editorial AIQUE.

Vigotsky, L.S. (1933/2004). Teoría de las Emociones. Madrid: Editorial AKAL. 